\section{Mycorrhizal Fungi in Rooting Substrate Influences the Quantity and Quality of Roots on Stem Cuttings of Hick's Yew}

\author{
C.F. Scagel, ${ }^{1}$ K. Reddy, ${ }^{2}$ and
} J.M. Armstrong ${ }^{2}$

\begin{abstract}
Additional indeX words. Glomus intraradices, Taxus $\times$ media 'Hicksii', VA mycorrhizae
\end{abstract}

SUmmary. In a commercial nursery propagation system for hick's yew (Taxus $\times$ media 'Hicksii'), we assessed whether or not the addition of inoculum of the vesicular-arbuscular mycorrhizal fungus (VAMF) Glomus intraradices into the rooting substrate during cutting propagation increased rooting, and how the quantity of inoculum influenced rooting. At 15 and 22 weeks ( 108 and $156 \mathrm{~d}$ ) after cuttings were treated with root hormones and stuck, root initiation was higher on cuttings stuck in the rooting substrate containing VAMF inoculum. Increasing the quantity of inoculum in the rooting substrate increased root growth during the early stages of rooting. However the highest level of inoculum tested increased adventitious root initiation without increased root growth. Our results indicate that if VAMF inoculum is used during propagation from

$\overline{\text { U.S. Department of Agriculture, Agricultural Research }}$ Service, Horticultural Crops Research Unit, 3420 NW Orchard Avenue, Corvallis, OR, 97330; e-mail scagelc@ucs.orst.edu.

We thank Meadow Lake Nursery for plant material and logistical support and Kathy Eggemeyer and Ben Jackson for technical assistance. Mention of a trademark, proprietary product, or vendor does not constitute a guarantee or warranty of the product by the U.S. Dept. of Agriculture and does not imply its approval to the exclusion of other products or vendors that also my be suitable.

${ }^{1}$ Research plant physiologist, U.S. Department of Agriculture, Agricultural Research Service, Horticultural Crops Research Unit, 3420 NW Orchard Avenue, Corvallis, OR, 97330; to whom reprint requests should be addressed; e-mail scagelc@ucs.orst.edu.

${ }^{2}$ Meadow Lake Nursery, 2500 N.E. Hawn Creek Road. P.O. Box 1302, McMinnville, OR, 97128. cuttings, there are optimal levels required to alter the initiation and growth of roots. For hick's yew, 1:100 or 2:100 (by volume) rates of $G$. intraradices in the rooting substrate increased the number of primary roots and growth of adventitious roots on cuttings above that achieved by using rooting hormone alone.

M ycorrhizae are symbiotic associations between plant plant roots and certain soil fungi that can enhance plant productivity (Pfleger and Linderman, 1994; Powell and Bagyaraj, 1984; Smith and Reid, 1997). Plants with mycorrhizae are potentially more effective at nutrient and water acquisition (Ames et al., 1983; Augé et al., 1986; Koide, 1991; and Schubert and Hayman, 1986), less susceptible to disease (Pfleger and Linderman, 1994), and can be more productive under growing conditions where nutrients and water may be limiting productivity (Miller and Jastrow, 1992). Vesicular-arbuscular mycorrhizal fungi are one type of mycorrhizal fungi that are commonly associated with the roots of horticultural crops. The benefits from root colonization by VAMF are thought to be highest when colonization occurs as early as possible during plant growth (Chang, 1994; Nemec, 1987). In the propagation of plants from cuttings, this means that maximum benefits from VAMF colonization would be obtained if inoculum is present during adventitious root formation.

The addition of mycorrhizal fungi into the rooting substrate during cutting propagation can increase rooting in different plants (Douds et al., 1995; Linderman and Call, 1977; Scagel, 2001; Scagel, 2000; Verkade and Hamilton, 1987; Verkade et al. 1988). However, few of these studies were conducted in production nurseries. Although commercially produced inoculum of VAMF is readily available to horticulturalists, the relationship, if any, between inoculum quantity and plant response is unclear.

Yew plants used for production of taxol, a medicinal chemical used as part of certain chemotherapy regimes, are commonly produced from cuttings (Shugert, 1997). When large quantities of rooted cuttings are required to be produced quickly, propa- gators look for methods to increase propagation success and decrease the time required for rooting (Armstrong, 2000 ). The number of roots initiated can influence the length of a production cycle and the quality of rooted cuttings produced. The objectives of this study were to determine 1) whether the addition of VAMF inoculum into the rooting substrate during cutting propagation increases rooting of hick's yew and 2) how the quantity of VAMF inoculum influences the rooting of hick's yew under nursery production conditions.

\section{Materials and methods}

Plant material. On Mar. 13, 2001, cuttings were manually taken from the previous year's growth on field-grown 7-year-old hick's yew plants fertilized with $107 \mathrm{~kg} \cdot \mathrm{ha}^{-1}$ (100 $\mathrm{lb} / \mathrm{acre}$ ) of ammonium nitrate during August 2000. Cuttings were trimmed to an average length of $15 \mathrm{~cm}$ (5.9 inches) using a prototype hydraulic Felco pruner (Agriculture Ergonomics, Davis, Calif.). The bottom $5 \mathrm{~cm}$ (2.0 inches) of each cutting was dipped into $10,000 \mathrm{mg} \cdot \mathrm{L}^{-1}$ (ppm) ZeroTol (BioSafe Systems, Glastonbury, Conn.) to disinfect the cutting of potential pathogens. Before sticking, cuttings were dipped for $5 \mathrm{~s}$ in $3000 \mathrm{mg} \cdot \mathrm{L}^{-1}$ Woods Hormone Solution (1.03\% indol-3-butyric acid and $0.66 \% 1$ napthalene acetic acid; Earth Science Products Corp., Wilsonville, Ore.), then stuck in $48 \times 15 \times 8-\mathrm{cm}(18.9 \times$ $5.9 \times 3.1$ inches $)$ flats filled with a custom blend of 15 coarse perlite : 1 peat moss : 3 sand (by volume) (ProGrow, Tualatin, Ore.). Flats contained about 120 cuttings in a $12 \times 10$ arrangement in each flat. The bottom 5 to $6 \mathrm{~cm}$ (2.0 to 2.4 inches) of each cutting was stuck vertically into the rooting substrate in flats.

Propagation environment. Flats of cuttings were kept in a opaque polycarbonate greenhouse under natural lighting and photoperiod in McMinnville, Ore. (lat. 4521'121" N, long. $123^{\circ} 19^{\prime} 024^{\prime \prime}$ W). Light quality and quantity was not measured during the experiment. Air temperatures were monitored daily and ranged from 12 to $24^{\circ} \mathrm{C}\left(54\right.$ to $\left.75^{\circ} \mathrm{F}\right)$ throughout the rooting period. Cuttings were provided with bottom heat of $17^{\circ} \mathrm{C}$ $\left(63^{\circ} \mathrm{F}\right)$ and were misted and watered as needed with water containing 200 $\mathrm{mg} \cdot \mathrm{L}^{-1}$ ZeroTol. The nursery's stan- 
dard disease and pest control measures were performed during the rooting period. General propagation environment and nursery practices for the propagation of hick's yew in this nursery are outlined by Armstrong (2000).

MycorRhizal inOCULUM. Glomus intraradices was originally obtained from Native Plants Inc., (Salt Lake City, Utah) and maintained in pot cultures at the USDA-ARS, Horticultural Crops Research Laboratory in Corvallis, Ore. The fungus was propagated in pot cultures on roots of bunching onion (Allium cepa 'White Lisbon') grown in a mixture of a 1 Willamette Valley alluvial silt loam : 1 river sand (by volume) $\left[11 \mathrm{mg} \cdot \mathrm{kg}^{-1}(\mathrm{ppm})\right.$ available (Bray) phosphorus (P), $\mathrm{pH}$ 6.3] for 5 months. Inoculum consisted of a mixture of the soil substrate, extraradical hyphae and spores, and colonized root segments $[<2 \mathrm{~mm}(0.08$ inches) long] with a bulk density of $4.74 \mathrm{~g} \cdot \mathrm{cm}^{-3}$. The MPN method (Woomer, 1994) was used to estimate the density of the inoculum which averaged 10 propagules/g (283 propagules/oz) of soil substrate. Before sticking cuttings, flats were halffilled with rooting substrate, an even layer of inoculum was placed on top of the rooting substrate, then the flats where filled with rooting substrate to within $1 \mathrm{~cm}(0.4$ inches) of the top of the flat. The treatments were no inoculum, and $1 \times, 2 \times$, and $3 \times$ treatments of VAMF created by a $1: 100$, $2: 100$, or 3:100 (by volume) ratio of inoculum to propagation substrate, respectively.

Data collection. Five cuttings per flat ( $15 /$ treatment $)$ were removed randomly from the rooting substrate 15 and 22 weeks ( 108 and 152 d) after the start of the experiment. At all harvest times, cuttings sampled from all treatments showed quantifiable levels of adventitious root formation. The primary and secondary roots on each cutting were counted and removed from the cutting. Fresh weights were obtained for aboveground (region above rooting zone) and root portions of each cutting. All samples were dried at $60^{\circ} \mathrm{C}\left(140^{\circ} \mathrm{F}\right)$ and dry weights were obtained after tissue had reached a constant dry weight (48 to $60 \mathrm{~h}$ ). VAMF colonization of fresh roots was assessed on $1-\mathrm{cm}$ sections after clearing and staining by modified procedures of Phillips and Hayman (1970), replacing lacto-phenol with lacto-glyc- erin. Percentage of root length with signs of VAMF colonization (arbuscular formation) was estimated by the method of Biermann and Linderman (1980).

EXPERIMENTAL DESIGN AND STATISTICAL ANALYSES. The experiment was set up in a nested-design with four inoculum levels (control, $1 \times, 2 \times$, and $3 \times$ ) and three replicate flats per treatment level $(r=3)$. Random samples of five cuttings per flat were included in analyses $(n=5)$. Data were subjected to a two-factor analysis of variance (ANOVA) using the Statistica statistical package (Statsoft, Inc., Tulsa, Okla.) with inoculation treatment and harvest date as main effects and flats considered a fixed-effect nested within inoculation treatment [flat(treatment)] as outlined by Winer (1971). Variation among samples within experimental units was determined using the sampling error term (MSS). Variation among flats of the same treatment was determined using the experimental error term (MSE). The ratio of MSE to MSS was used to calculate $\mathrm{F}_{\mathrm{E}}$ for testing the significance of the variation among flats within the same treatment. The residual error term was used to calculate $\mathrm{F}_{\mathrm{T}}$, test significance of differences among the treatment means and calculate standard errors of treatment means. Control plants showed no evidence of mycorrhizal colonization, therefore, colonization data were analyzed only for inoculum levels $1 \times, 2 \times$, and $3 \times$. Orthogonal contrasts were used to address the following questions: 1) Does addition of VAMF to the rooting substrate alter rooting? (contrast $\mathrm{l}$ : control versus all VAMF treatments); 2) How does the level of VAMF inoculum in the rooting substrate alter rooting? (contrast 2: linear or quadratic contrasts based on treatment levels); and 3) How is root colonization dependent on the quantity of inoculum (contrast 3: linear and quadratic contrasts based on treatment levels)? Fisher's protected LSD test was used to separate treatment means. The relationship between percentage root colonization and other variables was assessed using Pearson's correlation coefficient $(r)$.

\section{Results and discussion}

Root INITIATION. Adding VAMF into the rooting substrate significantly influenced the number of roots per cutting compared to controls at both harvest dates $\left(\mathrm{F}_{1,104}=23.8\right.$, MSE $=$ $6525, P<0.0004)$. There was a significant quadratic relationship between inoculum level and number of roots per cutting $\left(\mathrm{F}_{1.104}=36.15, \mathrm{MSE}=\right.$ $9889, P<0.0001)$. The number of primary roots were highest on cuttings stuck into the propagation substrate containing $2 \times$ treatment levels of inoculum, while cuttings stuck into substrate containing the $3 \times$ treatment level of inoculum had the same number of roots as $1 \times$ treatment (Fig. $1 \mathrm{~A})$. The response of root initiation to mycorrhizal inoculum was not significantly different between the different harvest dates $\left(\mathrm{F}_{3,104}=0.33, \mathrm{MSE}=91.8, P<\right.$ $0.7997)$.

Verkade and Hamilton (1987) found that the presence of $G$. fasciculatum in the rooting substrate increased root development and growth of arrowwood (Viburnum dentatum) but not root initiation. Scagel (2001) found that adding $G$. intraradices inoculum into the rooting substrate of miniature roses (Rosa spp.) did not always increase root initiation, but in some miniature rose cultivars, the combination of VAMF inoculum and rooting hormone increased root initiation. Our results indicate that adding $G$. intraradices inoculum to the rooting substrate of hick's yew increased root initiation and that the cuttings receiving the $2 \times$ treatment level showed the highest initiation of adventitious roots. The cultivar-specific responses with miniature roses reported by Scagel (2001) could have been due to this relationship between inoculum level and rooting response. The one level of inoculum used in this study with different cultivars of miniature roses may not have been the optimal level of inoculum for altering rooting response of all cultivars.

Root GRowth. Adding VAMF inoculum to the rooting substrate significantly influenced the dry weight of roots per cutting $\left(\mathrm{F}_{1,104}=10.07, \mathrm{MSE}\right.$ $=0.24, P<0.0019)$. However, the response to inoculation changed with harvest date $\left(\mathrm{F}_{1,104}=7.35\right.$, MSE $=$ $0.24, P<0.0078)$. At $108 \mathrm{~d}$, root weight significantly increased with increasing levels of inoculum in the rooting medium $\left(\mathrm{F}_{1,104}=13.71, \mathrm{MSE}=\right.$ $0.24, P<0.0003)$. The weight of roots was highest on cuttings stuck into the propagation substrate containing either the $2 \times$ and $3 \times$ treatment levels of 
inoculum, while cuttings stuck into the substrate containing the $1 \times$ treatment level of inoculum had the same weight of roots as control cuttings (Fig. 1B). At 156 d, there was a signifi-
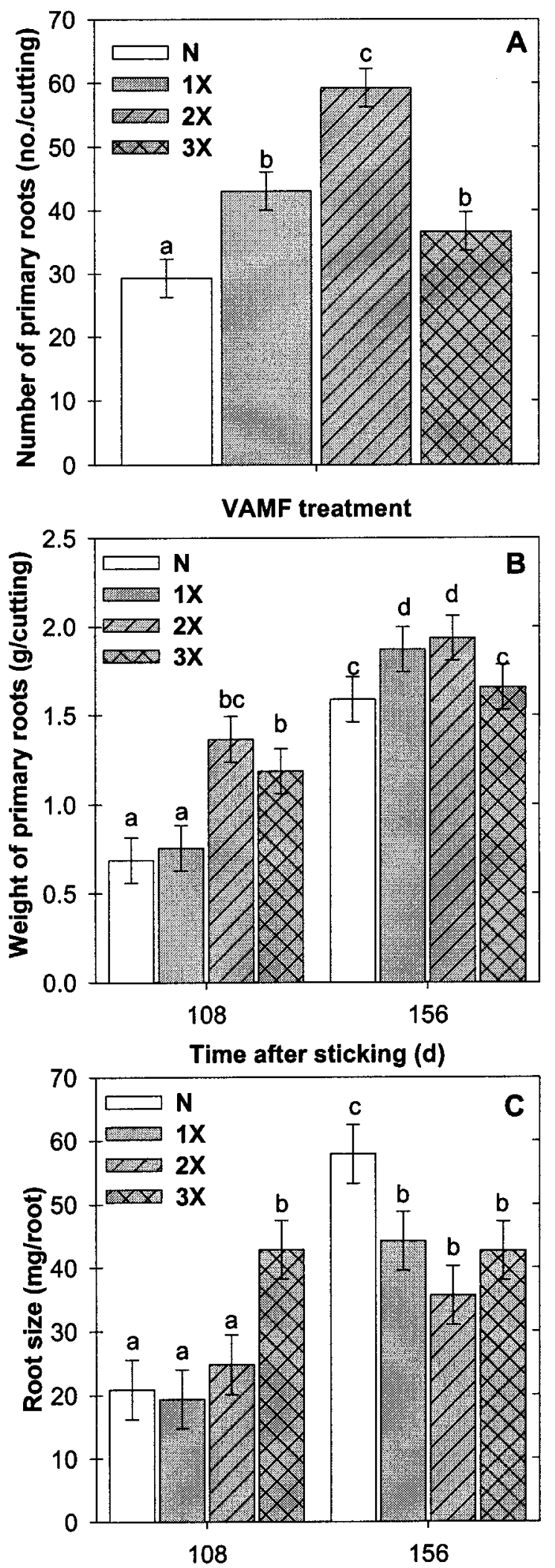

Time after sticking (d) cant quadratic relationship between inoculum level and root weight $\left(\mathrm{F}_{1104}\right.$ $=4.83, \mathrm{MSE}=0.24, P<0.0302)$. Root weight was lowest in the control cuttings and cuttings stuck into substrate containing the $3 \times$ level of inoculum.

With miniature roses, Scagel (2001), found that cuttings treated with the combination of rooting hormone and G. intraradicesinoculum had greater root weight when compared to cuttings from other treatments. Our results with hick's yew indicate that increasing the quantity of $G$. intraradices inoculum in the rooting substrate can increase root growth (in terms of root weight) during the early stages of rooting, but the $3 x$ level of inoculum can increase adventitious root initiation without increased root growth.

Root size. Adding VAMF inoculum to the rooting substrate significantly influenced root size (in terms of weight per root) but the type of response to inoculation depended on harvest date $\left(\mathrm{F}_{1,104}=10.98, \mathrm{MSE}=\right.$ $325, P<0.0013)$. At the first harvest, $108 \mathrm{~d}$ after sticking, only cuttings receiving the $3 \times$ inoculum level had larger roots than control cuttings (Fig. 1C). At the second harvest, $156 \mathrm{~d}$ after sticking, the average weight per root on

Fig. 1. Influence of the quantity of Glomus intraradicesinoculum [vesicular-arbuscularmycorrhizal fungus (VAMF) treatment] on the (A) number of roots, $(\mathrm{B})$ weight of roots, and $(C)$ average root size per cutting of hick's yew 108 and $152 \mathrm{~d}$ after cuttings were stuck. $\mathbf{C}=$ noninoculated controls; $1 \times, 2 \times$, and $3 \times$ levels of inoculum. Bars on columns representstandard errors. Different letters abovebars represent treatmentmeans significantly different from each other $(P<0.05$, Fisher's protected leastsignificant difference). $1 \mathrm{~g}=1,000 \mathrm{mg}=$ 0.035 oz. cuttings was lowest on cuttings exposed to $\operatorname{VAMF}\left(\mathrm{F}_{1,104}=10.1, \mathrm{MSE}=\right.$ $325, P<0.0006)$. Since root length and diameter were not measured in this study, it is impossible to state whether the larger roots were thicker or longer than cuttings from other treatments. This alteration in root size and anatomy on cuttings may influence the function of the new root system relative to water and nutrient uptake, as well as survival during transplanting.

Roots on miniature rose cuttings treated with rooting hormone are generally smaller (shorter and/or thinner) than roots on cuttings from untreated controls (Scagel, 2001). In that study, cuttings from miniature rose cultivars with $G$. intraradices inoculum in the rooting substrate had similar root size when compared to cuttings from untreated controls. Further experimentation is needed to determine how root size and anatomy on hormonetreated cuttings differ from roots on cuttings stuck in rooting substrate containing VAMF inoculum and on untreated controls. A detailed study on the anatomical differences between these roots could aid in determining the mechanism through which VAMF inoculum increases root initiation and growth in cuttings.

Biomass partitioning. New growth on cuttings was assessed using aboveground dry weight. There was a significant quadratic relationship between inoculum level and dry weight of cuttings $\left(\mathrm{F}_{1104}=11.99, \mathrm{MSE}=\right.$ $0.250, P<0.0008)$. Nontreated cuttings and cuttings receiving the highest levels of inoculum had the highest aboveground dry weight [1.67 and $1.76 \mathrm{~g}(0.059$ and $0.062 \mathrm{oz})$, respectively], while cuttings receiving the $1 \times$ and $2 \times$ levels of inoculum had significantly lower aboveground dry weight [1.34 and $1.42 \mathrm{~g}(0.047$ and 0.050 $\mathrm{oz}$ ), respectively]. We compared the ratio of aboveground dry weight to fresh weight to assess differences in tissue hydration and new growth between cuttings receiving different treatments. Noninoculated cuttings had a significantly higher ratio of aboveground dry weight to fresh weight than cuttings inoculated with $\operatorname{VAMF}\left(\mathrm{F}_{1,104}=36.50, P<0.0001\right)$ (Fig. 2A). Cuttings with the most roots and highest root weight had the lowest aboveground dry weight to fresh weight ratios suggesting that increased 
root initiation and growth increased levels of tissue hydration and growth in the aboveground portion of the cutting.

The size of the root system in

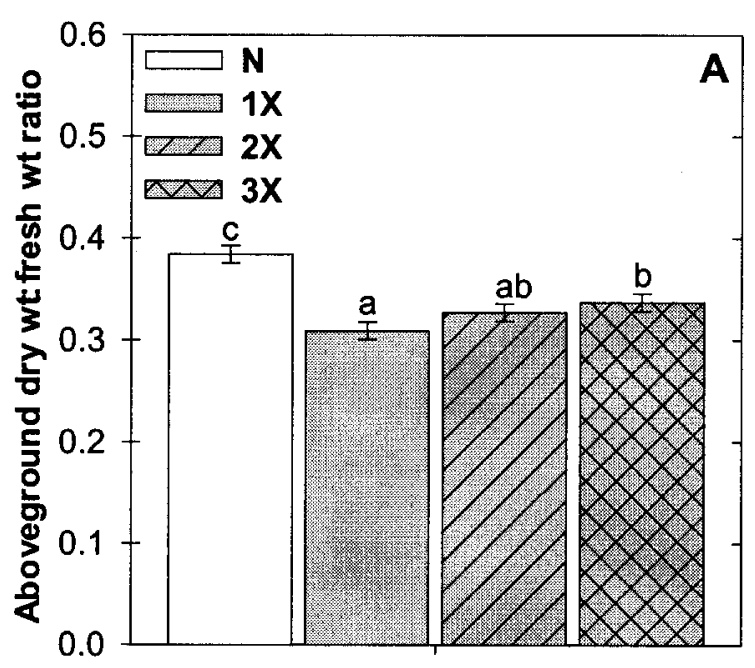

VAMF treatment

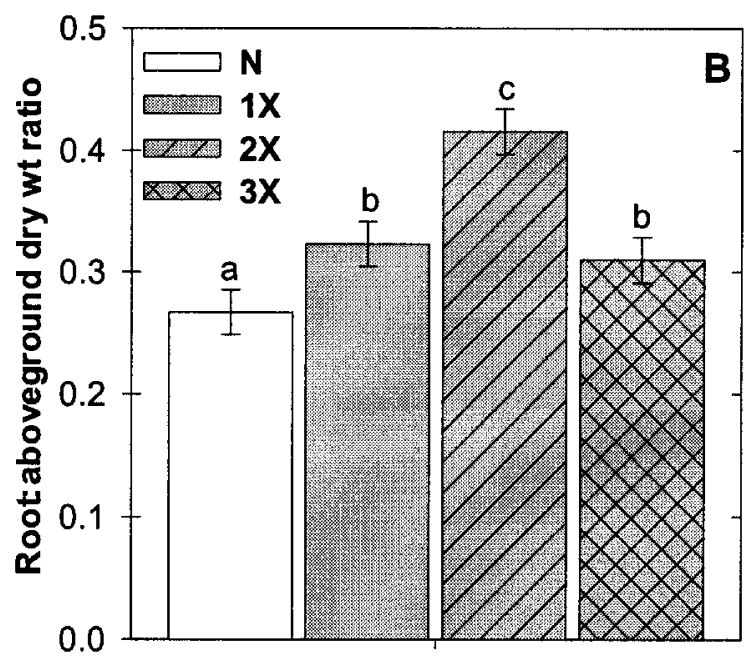

VAMF treatment

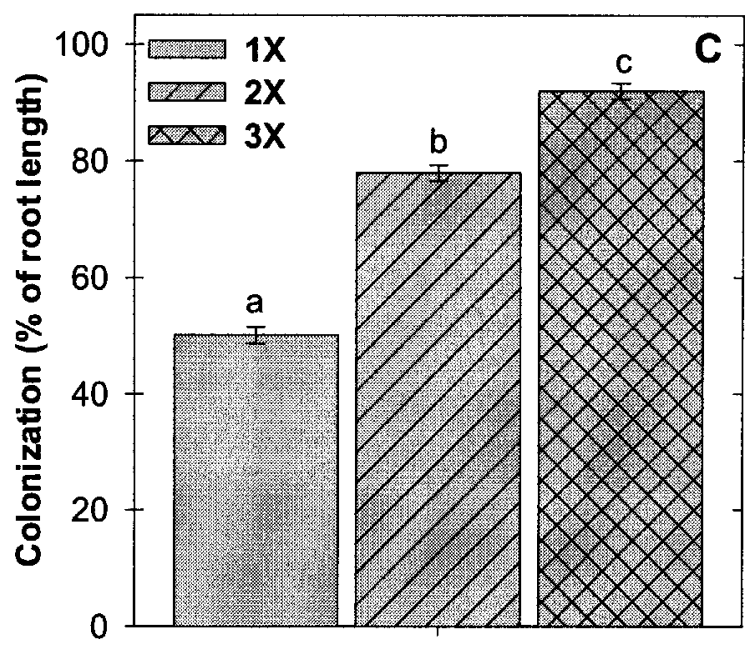

VAMF treatment relationship to the aboveground size of the cutting has implications to transplant survival and cutting quality. Cuttings with VAMF inoculum in the rooting substrate had significantly different ratios of root to aboveground dry weight than controls $\left(\mathrm{F}_{1104}=6.24\right.$, MSE $=0.024, P<0.014)$. Ratios of root to aboveground dry weight were highest on cuttings receiving the $2 \times$ inoculum level, while cuttings stuck into substrate containing the $3 \times$ treatment level of inoculum had the same root to aboveground dry weight ratio as $1 \times$ treated cuttings (Fig. 2B). This may be a result of the high colonization at the $3 \times$ inoculum level early during root development altering carbon partitioning in cuttings resulting in lowered root weight than cuttings receiving the $2 \times$ inoculum level treatment.

MycorRHIZAL COLONIZATION. Increasing the quantity of VAMF inoculum in the rooting substrate of hick's yew significantly influenced the root colonization by VAMF on cuttings $\left(\mathrm{F}_{178}=\right.$ $344, \mathrm{MSE}=79, P<0.0001)$. Root colonization was lowest on cuttings stuck into the propagation substrate con-

Fig. 2. Influence of the quantity of Glomus intraradicesinoculum [vesicular-arbuscularmycorrhizal fungus(VAMF) treatment] on the (A) ratio of aboveground dry to fresh weight, (B) ratio of root to aboveground dry weight, and (C) root colonization of hick's yewby Glomus intraradices $108 \mathrm{~d}$ after cuttings were stuck. $\mathbf{N}=$ noninoculated controls; $1 \times, 2 \times$, and $3 \times 1$ levels of inoculum. Control plants showed no signs of colonization (arbuscules). Barson columns representstandard errors. Different letters above bars represent treatment means significantlydifferent from each other $(P<0.05$, Fisher's protected least significant difference). $1 \mathrm{~g}=$ $1,000 \mathrm{mg}=0.035 \mathrm{oz}$. taining the $1 \times$ treatment level of inoculum, while the highest colonization was on cuttings stuck into substrate containing the $3 \times$ treatment level of inoculum (Fig. 2C). At the first harvest, $108 \mathrm{~d}$ after cuttings were stuck, root colonization on cuttings stuck into the propagation substrate containing G. intraradices was correlated to root number $(r=0.601, P<0.0147)$, root dry weight $(r=0.635, P<0.0124)$, and aboveground weight $(r=0.682, P$ $<0.0012)$. By the second harvest, only the ratio of stem dry weight to fresh weight was correlated with colonization level $(r=-0.761, P<0.0001)$. Using the same isolate of $G$. intraradicesas used in this study, Scagel (2001) found that the rooting on cuttings exposed to VAMF inoculum correlated with colonization for some cultivars of miniature roses.

Increased root initiation and root growth of hick's yew cuttings rooted in substrate containing VAMF inoculum were not always associated with increased levels of colonization. It is possible that the high colonization at the $3 \times$ inoculum level early during root development may have altered carbon metabolism and partitioning in cuttings resulting in lowered root initiation and growth than cuttings receiving the $2 \times$ inoculum level treatment. Verkade and Hamilton (1981) found that extensive mycorrhizal development occurred on roots of regal privet (Ligustrum obtusifolium var. regelianum) after 6 weeks of rooting in a substrate inoculated with $G$. mosseae. Mycorrhizal colonization coincided with substantially increased root development but no effects on root initiation were found. Verkade and Hamilton (1987) found that inoculation of arrowwood cuttings increased the number of root initials emerging from stem cuttings 5 weeks after sticking, but they concluded that this effect occurred only after colonization and was mediated through an effect of the fungus on plant metabolism rather than an effect of fungal exudates before colonization.

\section{Conclusions}

Although the degree of response of hick's yew cuttings to G. intraradices varied with the level of inoculum, our results indicate that adding inoculum into the rooting substrate of cuttings treated with rooting hormones is equal to or better than the rooting response 
obtained by using only rooting hormone under the nursery production conditions. When propagating nursery stock by cuttings, growers should run trials using different VAMF fungal species and inoculum levels to determine optimal levels of inoculum for response as well as economic benefit. Our results indicate that increasing the quantity of VAMF inoculum in the rooting substrate can increase root growth. However there may be levels of VAMF inoculum that increase root initiation without increased root growth.

In soilless substrates lacking mycorrhizal fungi, mycorrhizal inoculation has been found to increase crop uniformity, reduce transplant mortality, and increase productivity of different horticultural crops ( Powell and Bagyaraj, 1984; Vosatka, 1995; Vosatka et al., 1999). In our experiment, although all rates of VAMF inoculum did not increase root growth, the root colonization resulting from inoculation at certain rates could result in higher quality cuttings that are better able to withstand the stress of transplanting and increase growth during later stages of plant development.

\section{Literature cited}

Ames, R.N., C.P.P. Reid, L.K. Porter, and C. Cambardella. 1983. Hyphal uptake and transport of nitrogen from two ${ }^{15} \mathrm{~N}$-labelled sources by Glomus mosseae, a vesicular-arbuscular mycorrhizal fungus. New Phytol. 95:381-396.

Armstrong, J.M. 2000. Taxus production at Meadow Lake Nursery for Taxol production. Comb. Proc. Intl. Plant Prop. Soc. 50:595-597.

Augé, R.M., K.A. Schekel, and R.L. Wample. 1986. Greater leaf conductance of well-watered VA mycorrhizal rose plants is not related to phosphorus nutrition. New Phytol. 103:107-116.

Biermann, B. and R.G. Linderman. 1980. Quantifying vesicular-arbuscular mycorrhizae: A proposed method towards standardization. New Phytol. 87:63-67.
Chang, D.C. 1994. What is the potential for management of vesicular-arbuscular mycorrhizae in horticulture? p. 87-90. In: A.D. Robson, L.K. Abbot, and N. Malajczuk (eds.). Management of mycorrhizas in agriculture, horticulture, and forestry. Kluwer Academic Publishers. Dordrecht, The Netherlands.

Douds, D.D., G. Becard, P.E. Pfeffer, L.W. Doner, T.J. Dymant, and W.M. Kayer. 1995. Effect of vesicular-arbuscular mycorrhizal fungi on rooting of Sciadopitys verticillata Sieb \& Zucc. cuttings. HortScience 30:133-134.

Koide, R.T. 1991. Nutrient supply, nutrient demand and plant response to mycorrhizal infection. New Phytol. 117:365386

Linderman, R.G. and C.A. Call. 1977. Enhanced rooting of woody plant cuttings by mycorrhizal fungi, p. 106. In: D.H. Marx (ed.). Abstr. $3^{\text {rd }}$ N. Amer. Conf. Mycorrhizae. Athens, Ga. 23-25 Aug. 1977.

Miller, R.M. and J.D. Jastrow. 1992. The application of VA mycorrhizae to ecosystem restoration and reclamation. p. 438 468. In: M.F. Allen (ed.). Mycorrhizal functioning: An integrative plant-fungal process. Chapman and Hall, New York.

Nemec, S. 1987. VA mycorrhizae in horticultural systems, p. 193-211. In: G.R. Safir (ed.). Ecophysiology of VA mycorrhizal plants. CRC Press, Boca Raton, Fla.

Pfleger, F.L. and R.G. Linderman. 1994. Mycorrhizae and plant health, p. 337344. In: F.L. Pfleger and R.G. Linderman (eds.). Mycorrhizae and plant health. APS Press, St. Paul, Minn.

Phillips, J.M. and D.S. Hayman. 1970. Improved procedures for clearing roots and staining parasitic and vesiculararbuscular mycorrhizal fungi for rapid assessment of infection. Trans. Brit. Mycol. Soc. 55:158-160.

Powell, C.Ll. and D.J. Bagyaraj. 1984. Effect of mycorrhizal inoculation on the production of blueberry cuttings-A note. N.Z. J. Agr. Res. 27:467-471.

Scagel, C.F. 2000. Using mycorrhizal fungi during propagation of woody horticultural crops. Comb. Proc. Intl. Plant Prop. Soc. 50:589-594.
Scagel, C.F. 2001. Cultivar specific effects of mycorrhizal fungi on the rooting of miniature rose cuttings. J. Environ. Hort. 19:15-20.

Schubert, A. and D. Hayman. 1986. Plant growth responses to vesicular-arbuscular mycorrhiza XVI. Effectivness of different endophytes at different levels of soil phosphate. New Phytol. 103:79-90.

Shugert, R. 1997. Medicinal plants with a potential niche market for propagators. Comb. Proc. Intl. Plant Prop. Soc. 47:497498.

Smith, S.E. and D.J. Read. 1997. Mycorrhizal symbiosis. Academic Press, San Diego, Calif.

Verkade, S.D. and D.F. Hamilton. 1981. Mycorrhizae and their uses in the nursery. Proc. Intl. Plant Propagators Soc. 30:353362.

Verkade, S.D. and D.F. Hamilton. 1987. Effect of endomycorrhizal inoculum on root initiation and development of Viburnum dentatum L. cuttings. J. Environ. Hort. 5:80-81.

Verkade, S.D., L.C. Elson, and D.F. Hamilton. 1988. Effect of endomycorrhizal inoculation during propagation on growth following transplanting of Cornus sericea cuttings and seedlings. Acta Hort. 227:248-250.

Vosatka, M. 1995. Influence of inoculation with arbuscular mycorrhizal fungi on the growth and mycorrhizal infection of transplanted onion. Agr. Ecosystem Environ. 53:151-159.

Vosatka, M., J. Jansa, M. Regvar, F. Sramek, and R. Malcova. 1999. Inoculation with mycorrhizal fungi-A feasible biotechnology for horticulture. Phyton 39:219-244.

Winer, B.J. 1971. Statistical principles in experimental design. McGraw-Hill, New York.

Woomer, P.L. 1994. Most probable number counts, p. 59-79. In: R.W. Weaver (ed.). Methods of soil analysis. Part 2. Soil Sci. Soc. Amer., Madison, Wis. 